\title{
BIBLIOGRAFIA SOBRE TELENOVELA BRASILEIRA
}

\section{REVISTAS ESPECIALIZADAS}

BOUQUILLION, Philippe. La reception de telenovelas bresiliennes en France. Intercom: Revista Brasileira de Comunicação, São Paulo, v.15, n.1, jan./jun. 1992. p.98-117.

Enquanto em vários países do mundo as novelas brasileiras são amplamente difundidas, na França elas são praticamente ignoradas. Neste artigo, o autor traça as causas mais profundas deste desinteresse. Analisa desde a crise financeira e cultural do sistema de televisão face a um movimento crescente de internacionalização e mercantilização dos sistemas dos outros países. Apresenta as telenovelas brasileiras como modelo perfeito do que falta à televisão francesa, sendo, no entanto, dificilmente aceitas devido à transmissão de imagens não consensuais do Brasil e à melhor qualidade das séries americanas.

Palavras-chave: público francês, televisão francesa, internacionalização, telenovela brasileira

Loc. Doc. ${ }^{2}$ : BT/ECA/USP

N. Cham. ${ }^{3}: 301.16$

SOUZA, Lícia Soares de. Doze anos de merchandising no Brasil: um caso de relações públicas? Intercom: Revista Brasileira de Comunicação, São Paulo, v.14, n.65, jul./dez. 1991. p.6-18.

A partir de uma definição conceitual de gênero, a autora tem como objetivo oferecer aos profissionais de Relações Públicas subsídios para um trabalho crítico e reflexivo sobre a telenovela. Utiliza-se das teorias semiótico-comunicacionais para demonstrar

\section{A AUTORA}

\section{Anamaria Fadul}

Professora Titular do Departamento de Comunicações e Artes da.ECA-USP e Coordenadora do Núcleo de Pesquisas de Telenovelas $\left(\right.$ NPTN $\left.^{1}\right)$ deste Departamento.

1. O NPTN localiza-se à: Av. Prof. Lúcio Martins Rodrigues, 443 - Bloco Central, $2^{\circ}$ andar, sala CCA-6 - Cidade Universitária. CEP 05508-900 - São Paulo, SP. Telefax: (011) 818-4373.

2. Localização do Documento na Biblioteca da ECA-USP, no seguinte endereço: Av. Prof. Lúcio Martins Rodrigues, 443 - Bloco Central - Cidade Universitária. CEP 05508-900 - São Paulo, SP. Tel.: (011)

3. Número de chamada do documento no acervo da biblioteca. 
as relações entre o funcionamento discursivo do merchandising, especialmente em telenovela, e os contextos sociais nos quais as mensagens são veiculadas.

Palavras-chave: Relações Públicas, gênero, semiótica, merchandising, telenovela brasileira

Loc. Doc.: BT/ECA/USP

N. Cham.: 301.16

\section{DISSERTAÇÃO E TESE}

SPANIOL, Ênio Luís. Estudo dos efeitos da audiência: a telenovela das oito no meio rural do oeste catarinense. Porto Alegre, Brasil, Universidade Federal do Rio Grande do Sul, 1992. (Dissertação de Mestrado).

Analisa os efeitos da exposição de uma comunidade rural, localizada no município de São Miguel do Oeste, Santa Catarina, à telenovela. Tem por objetivo verificar as formas de expressão desta comunidade após um determinado período de exposição à telenovela Rainha da sucata, exibida pela Rede Globo. Como resultado, observou-se uma repetição por parte da população receptora, de gestos e maneiras de se expressar presentes no gênero estudado.

Palavras-chave: Rainha da sucata, recepção, comunidade rural, São Miguel do Oeste

Loc. Doc.: BT/ECA/USP

RIBEIRO, José Wagner. A TV artesanal. São Paulo, Escola de Comunicações e Artes. Universidade de São Paulo, 1993. 132p. (Dissertação de Mestrado).

Analisa a televisão artesanal no Brasil. Realiza um levantamento a partir da metade do século XIX, chegando até as pesquisas feitas, no Brasil, pelo técnico Olavo Bastos Freitas, em 1948. Aborda a inauguração da TV Tupi de São Paulo em 1950 e sua programação nos anos 50/60. Mostra a importância de alguns gêneros de programa, destacando-se o jornalismo, a telenovela, a programação infantil e as garotas-propaganda.

Palavras-chave: televisão artesanal, programação de televisão, década de 50, telenovela

Loc. Doc.: BT/ECA/USP 
ROCHA, Rosângela Vieira. Imagem desfocada: estudo sobre indústria cultural, ideologia e mulher. São Paulo, Escola de Comunicações e Artes. Universidade de São Paulo, 1982. 171p. (Dissertação de Mestrado).

Partindo de um panorama sobre o tratamento dispensado à mulher pelos meios de comunicação de massa como reprodutores da ideologia dominante, a autora recorta um universo desse panorama, as telenovelas, procurando examinar, a partir de uma análise de conteúdo, como é apresentada ao público a diferenciação entre os sexos. A novela analisada é Água viva. O método utilizado é baseado no modelo dos actantes proposto por Propp e completado por Greimas, além das abordagens de Simone de Beauvoir.

Palavras-chave: mulher, ideologia dominante, análise de conteúdo, diferenças sexuais, Água viva

Loc. Doc.: BT/ECA/USP

N. Cham.: t301.412/R672i

BUSTAMANTE, Maria Célia Fortes Santos de. TV e dinâmica familiar. Rio de Janeiro, Escola de Comunicação. Universidade Federal do Rio de Janeiro, 1980. 80p. (Dissertação de Mestrado).

A TV e sua contribuição nas transformações sociais, numa sociedade em mudanças e conseqüentes alterações da dinâmica familiar. Estudase a telenovela como produto de maior influência nas mudanças de atitudes e comportamentos. Na conclusão, aponta-se a responsabilidade dos comunicadores na elaboração da mensagem.

Palavras-chave: transformações sociais, dinâmica familiar, mudança de atitudes

Loc. Doc.: BT/ECA/USP

N. Cham.: t791.45/Bustamante 